\title{
Novel SCC mutation in a patient of Mexican descent with sex reversal, salt-losing crisis and adrenal failure
}

\author{
Jasmeet Kaur1,5, Alan M Rice 2,3,4, Elizabeth O’Connor1, Anil Piya2,4, Bradley Buckler ${ }^{4}$ \\ and Himangshu S Bose ${ }^{1,5}$
}

'Laboratory of Biochemistry, Biomedical Sciences, Mercer University School of Medicine, Savannah, Georgia, USA, 2Division of Pediatric Endocrinology, Memorial University Medical Center, Savannah, Georgia, USA, ${ }^{3}$ Augusta University School of Medicine, Augusta, Georgia, USA, ${ }^{4}$ Neonatology Intensive Care Unit, Memorial University Medical Center, Georgia, USA, and ${ }^{5}$ Anderson Cancer Institute, Memorial University Medical Center, Savannah, Georgia, USA

\author{
Correspondence \\ should be addressed \\ to $\mathrm{H}$ S Bose \\ Email \\ bose_hs@mercer.edu
}

\begin{abstract}
Congenital adrenal hyperplasia (CAH) is caused by mutations in cytochrome P450 side chain cleavage enzyme (CYP11A1 and old name, SCC). Errors in cholesterol side chain cleavage by the mitochondrial resident CYP11A1 results in an inadequate amount of pregnenolone production. This study was performed to evaluate the cause of salt-losing crisis and possible adrenal failure in a pediatric patient whose mother had a history of two previous stillbirths and loss of another baby within a week of birth. CAH can appear in any population in any region of the world. The study was conducted at Memorial University Medical Center and Mercer University School of Medicine. The patient was admitted to Pediatric Endocrinology Clinic due to salt-losing crisis and possible adrenal failure. The patient had $\mathrm{CAH}$, an autosomal recessive disease, due to a novel mutation in exon 5 of the CYP11A1 gene, which generated a truncated protein of 286 amino acids compared with wild-type protein that has 521 amino acids (W286X). Although unrelated, both parents are carriers. Mitochondrial protein import analysis of the mutant CYP11A1 in steroidogenic MA-10 cells showed that the protein is imported in a similar fashion as observed for the wild-type protein and was cleaved to a shorter fragment. However, mutant's activity was $10 \%$ of that obtained for the wild-type protein in non-steroidogenic COS-1 cells. In a patient of Mexican descent, a homozygous CYP11A1 mutation caused CAH, suggesting that this disease is not geographically restricted even in a homogeneous population.
\end{abstract}

\section{Learning points:}

- Novel mutation in CYP11A1 causes CAH;

- This is a pure population from Central Mexico;

- Novel mutation created early truncated protein.

\section{Background}

Protein targeting to a specific cellular compartment depends on two principal criteria: (1) the signal sequence and (2) maintenance of protein folding. Incorrect folding of metabolic enzymes present in the steroidogenic pathway leads to the reduced production of steroids necessary for mammalian development (1). There are many genes involved in the steroidogenic pathway, and a mutation in one has the potential to negatively impact the production 
of cortisol and induce adrenal enlargement, a condition known as congenital adrenal hyperplasia (CAH). A common feature in these mutations is the development of salt-losing crisis and ambiguous genitalia. Although it may be challenging to identify the gene responsible for reduced or low baseline steroid synthesis and subsequently ambiguous genitalia (2), the problem often starts with the availability of first steroid synthesized, pregnenolone, because the synthesis of all steroids depends on (i) cholesterol flow into the mitochondria and (ii) cleavage of the side chain of cholesterol to generate pregnenolone.

The steroidogenic acute regulatory protein (StAR) fosters cholesterol from the outer to inner mitochondrial membrane; thus, StAR mutations that impact this activity result in low levels of pregnenolone $(2,3)$. Although some mutations are more common in some specific ethnicities, StAR mutations are present in any ethnicity independent of the country of origin. In addition, mutations in the cytochrome $P 450$ side chain cleavage enzyme (CYP11A1) gene may render the protein inactive and result in low pregnenolone synthesis $(3,4)$. Thus, a full-term pregnancy is likely not to have any disorder in progesterone synthesis due to mutant CYP11A1. In contrast, low levels of progesterone and miscarriage may be due to CYP11A1 mutations that impact pregnenolone to progesterone conversion.

In addition to the correct folding, the activity of CYP11A1 depends on ferrodoxin, ferrodoxin reductase and NADPH, which are associated with several mitochondrialresident proteins, generating a large molecular weight complex $(5,6)$. Here, we report for the first time a de novo mutation in CYP11A1 that causes CAH identified in an infant of Mexican descent. The point mutation in exon 5 resulted in a truncated protein that is processed into the mitochondria in a fashion similar to that observed for wildtype CYP11A1. Both parents are carriers of this mutation, which is likely responsible for two previous abortions and the death of a previous newborn. Thus, although CAH is considered autosomal, it may also appear independent of genetic origin and as a result of the founder effect. We overexpressed this mutant CYP11A1 and determined its activity, folding and expression and compared it with the wild-type protein.

\section{Case presentation}

The proband was born by emergency C-section due to an approximately $10 \%$ placental abruption at 36 weeks and 1 day gestational age with a birth weight of $2416 \mathrm{~g}$ (26-50th percentile-for-gestational age), birth length of $46.8 \mathrm{~cm}$ (26-50th percentile-for-gestational age) and a head circumference of $34.5 \mathrm{~cm}$ (76-90th percentilefor-age). APGARS were 5 at $1 \mathrm{~min}$ and 7 at $5 \mathrm{~min}$ and 9 at $10 \mathrm{~min}$. Prenatal ultrasound revealed a nuchal fold. Amniocentesis was refused by the mother.

The parents were originally from Central Mexico. A pedigree analysis is presented in Fig. 1A. At the time of proband's birth, the mother was G4, P4 A2. The prior live-born infant, reportedly appeared female, was born at 23 weeks and 5 days gestational age with a weight of $600 \mathrm{~g}$ (51-75th percentile-for-gestational age) vaginally as a result of preterm labor, had multiple extreme prematurityrelated problems, including anemia, hypotension, grade IV intraventricular hemorrhage, renal dysfunction, patent ductus arteriosis, pulmonary intersititial emphysema of the newborn, thrombocytopenia, neonatal hypocalcemia followed by hypercalcemia, hyperbilirubinemia of prematurity, hypo- and hyperglycemia and electrolyte abnormalities - initially hypernatremia accompanied by eukalemia, followed by hyponatremia and hyperkalemia during the last $24 \mathrm{~h}$ of life. Newborn screening $17-\mathrm{OH}$ progesterone level on the second day of life was reported to be 'within normal limits', and a total $\mathrm{T}_{4}$ was reported as $<3.0 \mu \mathrm{g} / \mathrm{dL}$, whereas the $\mathrm{TSH}$ was reported to be
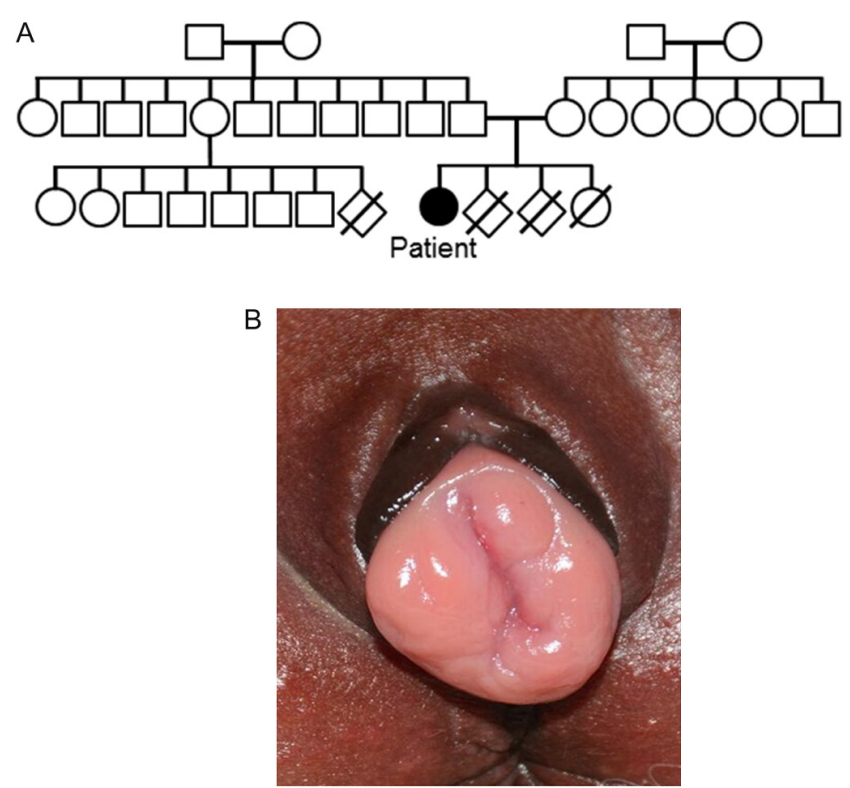

Figure 1

Pedigree and imaging analysis of a newborn patient presenting with salt-losing crisis and possible adrenal failure. (A) Pedigree analysis of the family: Black symbol represents affected individual and white symbols show unaffected individuals. The symbol (ठ) represents female, (古) male, preterm delivery of male $(\varnothing)$ and $(\varnothing)$ female who died prematurely.

(B) A close view of ambiguous genitalia. 
$2.3 \mu \mathrm{IU} / \mathrm{mL}$. The infant died on the 10th day of life of the complications of extreme prematurity and, in accordance with parental request, an autopsy was not done. The other two pregnancies concluded with spontaneous abortions. Because of the prior spontaneous abortions, and the extremely premature birth of the sibling, the mother of the proband received weekly injections of 17-hydroxyprogesterone caproate from 16 to 35 weeks of gestation. The last injection of 17-hydroxyprogesterone caproate (7) was received 1 week before the proband was born.

The proband infant had a prolapse of the upper vaginal region into the vaginal introitus with no visible secretions, partial labial-scrotal fusion, a $5 \mathrm{~mm}$ wide phallic structure with the urethral opening at the base, and no palpable gonads in the labial-scrotal folds (Fig. 1B). A chromosome analysis was ordered because of ambiguity of the genitalia (Fig. 1B). The infant was noted to have generalized hyperpigmentation, even when considering the Mexican ethnicity of the parents. The chromosome analysis revealed a 46, XY karyotype. On the sixth day of life, adrenocorticotropic hormone (ACTH) level was $3975 \mathrm{pg} / \mathrm{mL}$ (5-46 pg/mL), cortisol level was undetectable at less than $0.4 \mu \mathrm{g} / \mathrm{dL}$, plasma renin activity was $141.6 \mathrm{ng} / \mathrm{mL} / \mathrm{h}$ (normal, $2.0-35.0 \mathrm{ng} / \mathrm{mL} / \mathrm{h}$ ), progesterone was $<0.10 \mathrm{ng} / \mathrm{mL}$, 17 -hydroxyprogesterone was $<10 \mathrm{ng} / \mathrm{dL}$ (29-35 weeks gestational age normal range $26-568 \mathrm{ng} / \mathrm{dL}$ ), dihydroepiandrosterone (DHEA) was $<0.050 \mathrm{ng} / \mathrm{mL}$ (premature normal range $<40 \mathrm{ng} / \mathrm{mL}$ ) and androstenedione was $<0.030 \mathrm{ng} / \mathrm{mL}$ (31-35 weeks gestational age normal range $0.80-4.46 \mathrm{ng} / \mathrm{mL}$ ). The chromosome analysis, ACTH, plasma renin activity, steroids, with the exception of the cortisol, and their reference ranges are from ARUP LABORATORIES (Way, Salt Lake City, UT, USA). The serum glucose level was $58 \mathrm{mg} / \mathrm{dL}$, sodium was $130 \mathrm{mmol} / \mathrm{L}$ and the potassium was $5.7 \mathrm{mmol} / \mathrm{L}$, and the infant was noted to be tachypneic and to have subcostal retractions. Stress doses of hydrocortisone sodium succinate were started.

When the tachypnea and retractions resolved, the serum sodium, potassium and glucose levels were stably within the normal ranges for age, the hydrocortisone sodium succinate was replaced with physiologic replacement doses of prednisone, as well as 9-alphafludrocortisone and sodium chloride supplementation. Since then, the infant's linear growth and rate of weight gain have been normal, and the upper portion of the vagina is no longer protruding from the vaginal introitus. The adrenal gland was observed to be enlarged. The parents have opted to raise the child as a female unless the child opts for a male gender at an older age.

\section{Investigation}

Study participants: Informed consent was obtained from each participating family member as well as the parents of the patient with putative $\mathrm{CAH}$.

Sequence analysis: Blood samples collected in ethylenediaminetetraacetate were used to prepare genomic DNA using a genomic DNA isolation kit (DNeasy Blood and Tissue Kit, Qiagen). Because the patient was considered to have lipoid CAH, seven exons of StAR gene were analyzed following a standard procedure (3). Analysis of the CYP11A1 gene was also undertaken by first amplifying the genomic DNA using a variety of primer combinations (8), where we first amplified exons 1 and 2, which was similar to wild-type CYP11A1. We then amplified the rest of the exons using identical PCR conditions as previously described (8). PCR products were sequenced directly using commercial resources (MC Lab, South San Francisco, CA, USA).

Restriction fragment length polymorphism (RFLP) analysis: After the amplification of exon 5 using genomic DNA with primers SCC5S and SCC5AS as previously described (8), the resultant $282 \mathrm{bp}$ product was incubated with $\mathrm{BfaI}$ at $37^{\circ} \mathrm{C}$ for $45 \mathrm{~min}$. The bands were resolved in a non-denaturing 8\% TBE acrylamide gel after electrophoresis at $60 \mathrm{~V}$ for $2 \mathrm{~h}$ and were visualized after staining with ethidium bromide.

Cell culture, transfection and activity analysis: COS-1 cells were grown in DMEM medium supplemented with $5 \%$ fetal bovine serum, $10 \%$ horse serum and $1 \times$ gentamycin at $37^{\circ} \mathrm{C}$ in a humidified incubator under $5 \% \mathrm{CO}_{2}$. For CYP11A1 expression and activity, the mutant or wild-type CYP11A1 subcloned in $\mathrm{PCMV}$ vector and the purified plasmid cDNA was transfected with Lipofectamine as previously described (3). The cells were washed with serum-free media $12 \mathrm{~h}$ after transfection and supplemented with media containing the appropriate antibiotics and $10 \%$ serum. In all cases, $100 \mathrm{ng} / \mathrm{mL}$ of trilostane (Steraloids, Los Angeles, CA, USA) was added as

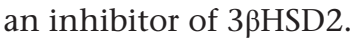

Metabolic conversion of cholesterol to pregnenolone was performed with reactions initiated with $\mathrm{NADPH}$ and ${ }^{14} \mathrm{C}$-cholesterol for pregnenolone synthesis. For complete conversion, we used five-fold excess of cold water-soluble cholesterol carrier to reach the saturation point. Trilostane was added in all the reactions to inhibit $3 \beta \mathrm{HSD} 2$ activity. Equal amounts of cold cholesterol-pregnenolone in ethanol were added as a carrier; the steroids were extracted with ether/acetone $(9: 1 \mathrm{v} / \mathrm{v})$, and the solvent was evaporated under $\mathrm{N}_{2}$. 
It was completed with the addition of five-fold excess of cold pregnenolone. The extract was brought up in $100 \mu \mathrm{L}$ of methanol, and radioactive counts were determined. The extracts were concentrated under a stream of nitrogen or air and then separated by TLC (Whatman, MA, USA) using a chloroform/ethyl acetate (3:1) mobile phase.

Mitochondrial translocation assay: A cell-free transcription/translation kit (Promega), which contains rabbit reticulocyte lysate (RRL) for protein expression after our modified procedure (6), was used to express wildtype and W286X CYP11A1-mutant proteins for in vitro experiments. Briefly, a mixture of 19 amino acids without cold methionine was incubated with ${ }^{35}$ S-methionine, (MP Biomedicals, Santa Ana, CA, USA) and SP6 polymerase at $26^{\circ} \mathrm{C}$ for $2 \mathrm{~h}$. Expression was verified using SDS-PAGE. For mitochondrial import analysis, mitochondria isolated from MA-10 cells were suspended in $20 \mathrm{mM}$ HEPES, $\mathrm{pH} 7.5$, following a previously described procedure $(3,4,5,6)$. After addition of the freshly prepared cell-free synthesized (CFS) protein of interest, mitochondria were incubated at $26^{\circ} \mathrm{C}$. To inhibit the mitochondrial proton pump, $1.0 \mu \mathrm{g} / \mathrm{mL}$ valinomycin (Sigma) was added.

\section{Outcome and follow-up}

We have performed a pedigree analysis of the patient's family, which shows that all the grandparents were from the same village and of the same ethnic origin (Fig. 1A). The grandparents lived a very long life with the paternal side living close to 100 years or more and the maternal side living more than 95 years. The parent's cousins were all living, and no major genetic defect, physical disability or abnormality was known to the parents of the patient.

We first considered that the ambiguous female genitalia and adrenal insufficiency were possibly due to a mutation in the $7.5 \mathrm{~kb}$ StAR gene, which has seven exons with exon 5-7 comprising $40 \%$ of the protein. Although mutations have been identified in other exons, most StAR mutations causing lipoid CAH have been found in exons 5-7 of the StAR gene (3). Because we did not find any mutation in exons $4-7$, we sequenced the complete gene but found no nucleotide changes in the StAR coding sequence even in the exon and intron boundary.

After revisiting the phenotypic data and finding that the mother had a problem retaining pregnancy, suggesting an inadequate supply of progesterone, we next analyzed all nine exons of the CYP11A1 gene using a combination of primers used previously (8). We identified a change in nucleotide 857, which changed from guanine to adenine, mutating tryptophan 286 to a stop codon (Fig. 2A). To confirm the presence of the mutation, we next amplified exon 5, including its intron-exon boundaries with the appropriate primers and performed RFLP analysis with BfaI because a TGG-to-TAG nucleotide change would destroy a BsrI restriction site at position 286 and simultaneously create a new BfaI restriction site (Fig. 2B and C). As shown in Fig. 3A, RFLP analysis using PCR-amplified product of exon 5 ( $282 \mathrm{bp}$ ) from the patient, mother and father confirmed the presence of the mutation, resulting in two bands of 202 and $80 \mathrm{bp}$ in the patient. The wild-type product was not digested at all because of the absence of the BfaI restriction site. However, both of the parents showed a similar, partial

A

CT ACT G GGAAT T G

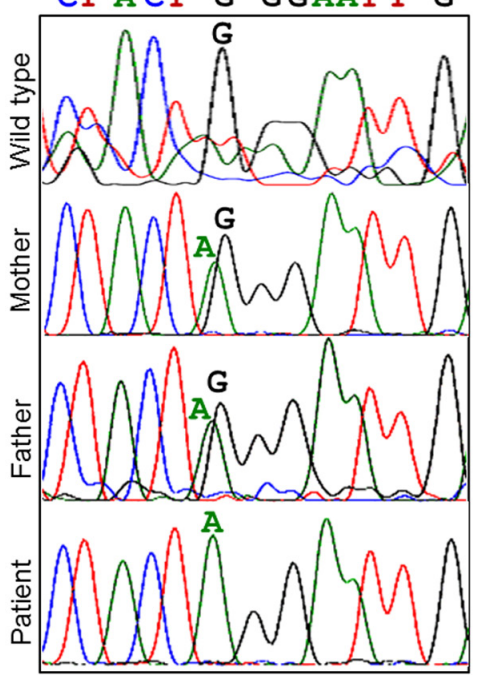

B

WT 29622-AACTTCTACTGGGAATTGAGA-29642 TTGAAGATGACCCTTAACTCT $\mathrm{G}>\mathrm{A}$

PT 29622 -AACTTCTACTAGGAATTGAGA-29642 TTGAAGATGATCCTTAACTCT Bfal

C

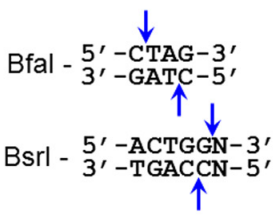

Figure 2

Sequencing analysis of the CYP11A1 gene. (A) Sequencing of the genomic DNA isolated from the patient, patient's parents and a control, unaffected individual with SCC5S and SCC5AS primers. A change in nucleotide 857 was found, which changed guanine to adenine, resulted in a mutation of tryptophan 286 to a stop codon. The father and mother were both heterozygous carriers of the mutation. (B) The $G$ to A mutation created a Bfal restriction site but destroyed a Bsrl site, shown by the indicated arrow. (C) Restriction enzyme nucleotide recognition sites of the Bfal and Bsrl. 


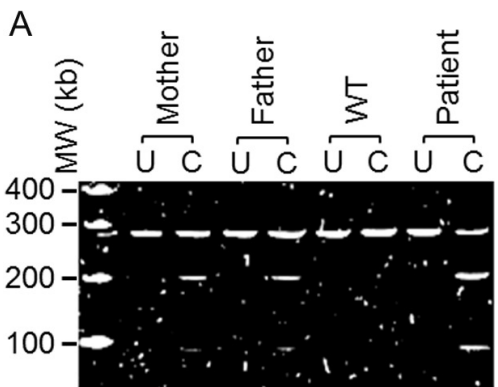

B
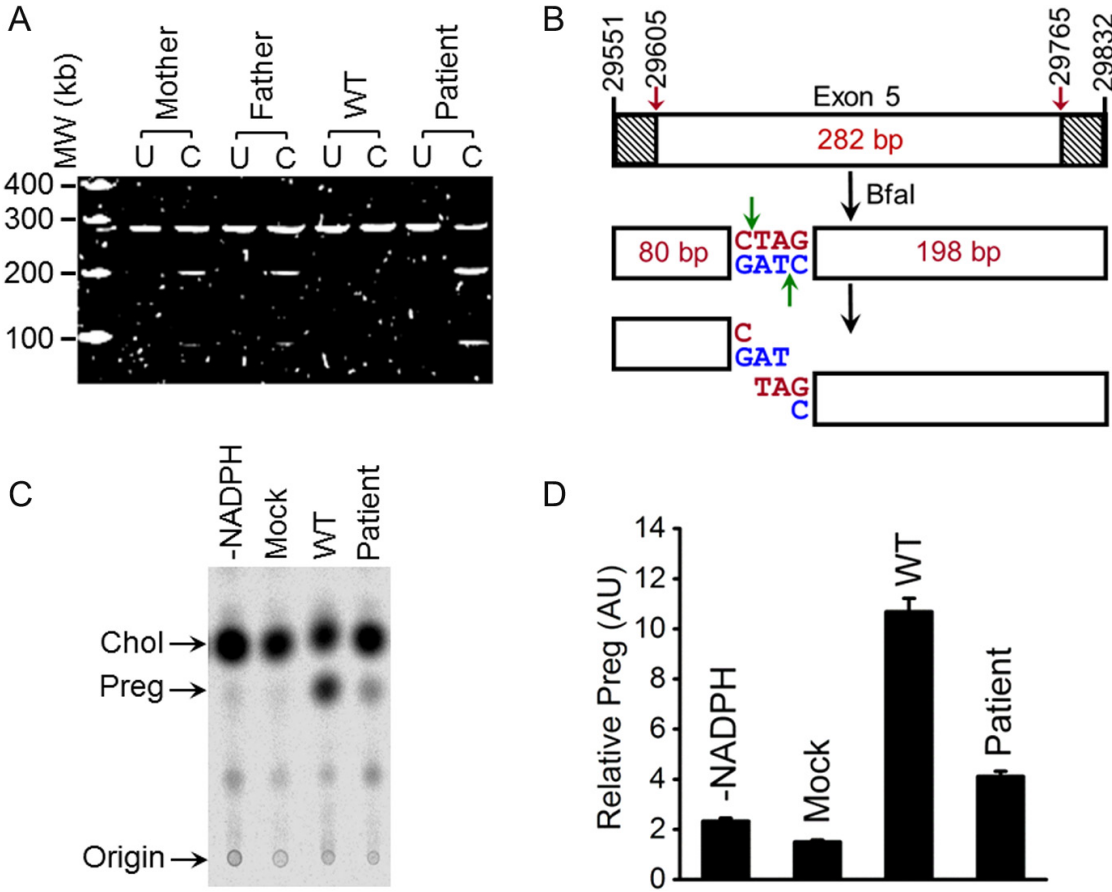

D

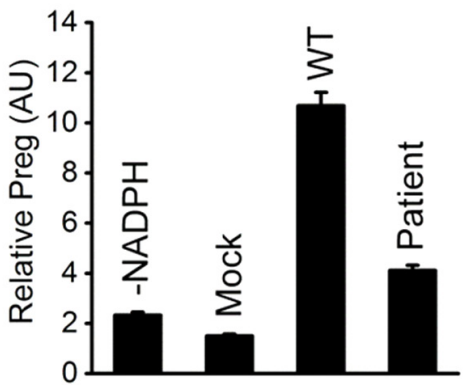

Figure 3

Analysis of the CYP11A1 mutation by RFLP and its effect on pregnenolone synthesis. (A) RFLP analysis of the $282 \mathrm{bp}$-amplified exon 5 of CYP11A1 followed by incubation with Bfal. Although the wild-type product is not digested, the product amplified from the patient was digested into two bands ( 202 and $80 \mathrm{bp}$ ).

The mother and father are both carriers, resulting in partial digestion. (B) Schematic analysis of the digestion pattern of the restriction analysis by Bfal. The hatched bar represents the exon-intron boundary. Digestion at the Bfal site results in two smaller fragments of 80 and $202 \mathrm{bp}$. (C) Measurement of pregnenolone synthesis by the W286X mutant and wild-type CYP11A1 after their expression in nonsteroidogenic COS-1 cells. (D) Quantitative analysis of the amount of steroid synthesized through phosphorimaging. The $\mathrm{Y}$-axis is presented in arbitrary units $(A U)$ developed by phosphoimager program. Data represent the mean \pm S.E.M. of three independent experiments performed at three different times. digestion with the intensities of the digested bands being $50 \%$ less as compared with the patient's sample, showing that both parents were carriers. The RFLP analysis is presented schematically (Fig. 3A), including the position of the exon with its intronic boundaries (Fig. 3B).

After overexpression of the wild-type and mutant CYP11A1 in non-steroidogenic COS-1 cells that were also transfected with ferrodoxin, ferrodoxin reductase and P450scc as a single fusion protein, F2 (3), analysis of pregnenolone synthesis revealed that the wild-type vector synthesized 8-fold more pregnenolone compared with the mutant CYP11A1 (Fig. 3C and D), suggesting that W286X truncated CYP11A1 reduced progesterone synthesis but not to that level of complete inactivity.

To understand whether the inactivity of the mutant was due to the shorter protein sequence and/or whether it was incapable of interaction with mitochondrial translocases and, therefore, mitochondrial translocation, we compared the mitochondrial import of the W286X CYP11A1 mutant with wild-type CYP11A1 using radiolabeled CYP11A1 obtained via cell-free rabbit reticulocyte system (CFS) and mitochondria isolated from the steroidogenic mouse Leydig (MA-10) cells. As shown in Fig. 4A, the $61 \mathrm{kDa}$ protein is imported into the mitochondria in two successive steps, resulting in 57 and $54 \mathrm{kDa}$ proteins. The 61 and $57 \mathrm{kDa}$ proteins were quickly proteolyzed by proteinase $\mathrm{K}(\mathrm{PK})$ in the presence of Triton X-100; however, the 54-kDa protein was resistant, suggesting that it was protected by the inner mitochondrial environment (Fig. 4A, last lane). Triton X-100 forms elliptical micelles on the membrane and makes an easy entry of the protease resulting in faster proteolysis. CYP11A1 was imported into the mitochondrial matrix as a $54 \mathrm{kDa}$ protein, so a shorter incubation of PK and Triton X-100 together protected mostly the protein fragment imported into the matrix (Fig. 4A, Right hand Panel). Interestingly, the $31-\mathrm{kDa} \mathrm{W} 286 \mathrm{X}$ mutant was also imported into the mitochondria and processed into a shorter 27-kDa band (Fig. 4B), suggesting that the CYP11A1 signal sequence is sufficient for mitochondrial transport. However, the regions required for interaction with the cofactors necessary for performing the enzymatic action may be lost in the truncated protein. To confirm the accuracy of the mitochondrial import and processing assay, we confirmed the quality of the mitochondria by importing cell-free synthesized CYP11A1 into the isolated mitochondria with the inhibition of the mitochondrial proton pump after incubation with $1.0 \mu \mathrm{g} / \mathrm{mL}$ valinomycin (Fig. 4C). CYP11A1 import was inhibited by valinomycin as indicated by the presence of only the 61 and $57 \mathrm{kDa}$ proteins, thus validating our mitochondrial import and processing analysis.

\section{Discussion}

Progesterone synthesis by mitochondrial 3ßHSD2 $(2,3,4)$ is required for the maintenance of human pregnancies as it suppresses uterine contractility, and interruption in the 


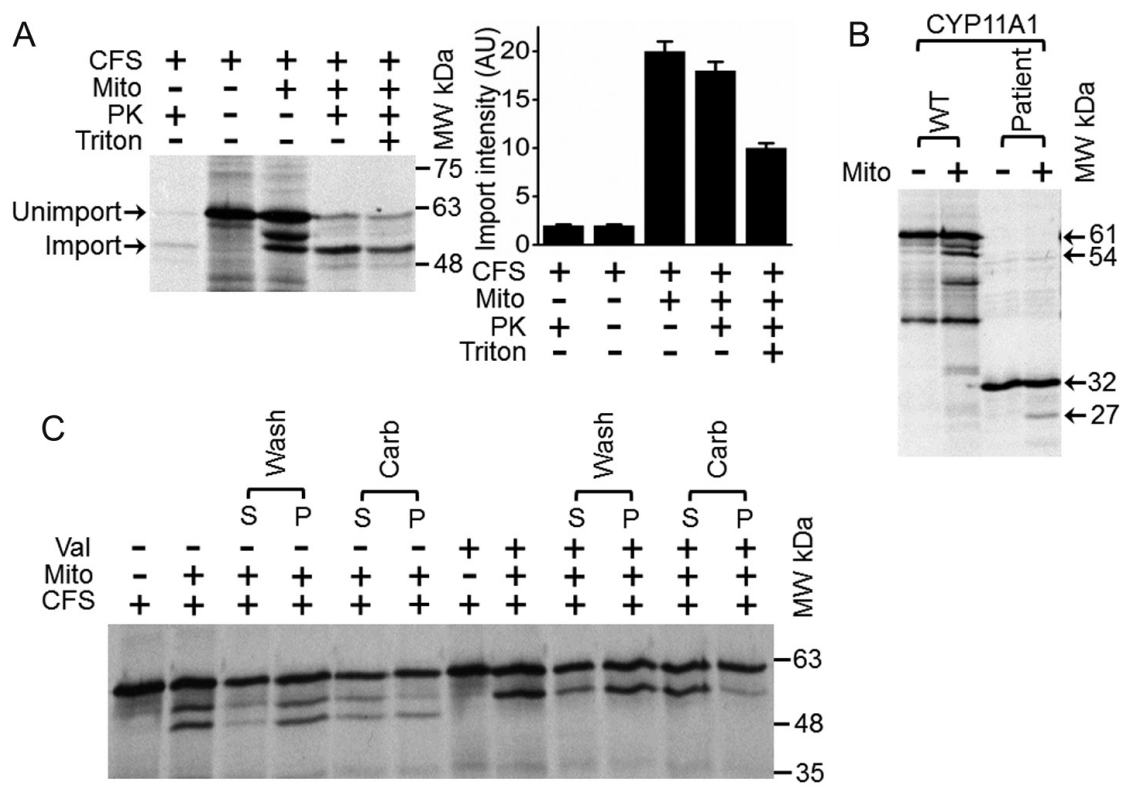

\section{Figure 4}

Mitochondrial import of the wild-type and W286X-mutant CYP11A1. (A) Left panel - 35S-Methionine-labeled wild-type CYP11A1 was synthesized in a linked cell-free rabbit reticulocyte lysate system (CFS) and then the newly synthesized protein was imported into mitochondria (mito) isolated from MA-10 cells. The import analysis was performed with proteinase K (PK) proteolysis in the presence and absence of Triton X-100 (Triton) and was visualized by autoradiography. The full-length protein is unimported (unimport) and mitochondrial resident fraction is imported (import). Right panel - Quantitative analysis of imported CYP11A1 in isolated mitochondria (54 kDa band), protected after PK and triton treatment. Data presented in this panel are a mean \pm S.E.M. of at least three independent experiments performed at three different times. (B) Comparison of wild-type (WT) and W286X mutant (patient) CYP11A1 into the isolated mitochondria (mito). The 31-kDa mutant protein was also imported and processed in the mitochondria into a shorter 27-kDa protein. (C) ${ }^{35}$ S-Methionine-labeled wild-type CYP11A1 was synthesized in a linked cell-free transcription translation system (CFS) and imported into mitochondria isolated from MA-10 cells (mito). The mitochondrial imported and unimported fractions were separated by washing (Wash) followed by centrifugation, where the unimported fraction remained in the supernatant (S), and the imported fraction remained in the pellet ( $P$ ). Sodium carbonate (Carb) determines the lipid integrated from the unintegrated protein. Addition of $1.0 \mu \mathrm{g} / \mathrm{mL} \mathrm{mitochondrial} \mathrm{uncoupler,} \mathrm{valinomycin}$ (Val) inhibited the proton pump from the matrix to the inner mitochondria space and thus only two bands were observed. The positive (+) and negative (-) symbols indicate the presence and absence of the indicated reagents.

maintenance of progesterone level induces abortion. As Miller's group has considered, no mutation of the placental ferrodoxin, ferrodoxin reductase and $3 \beta \mathrm{HSD} 2$ was reported and none of the START domain proteins can compensate for the loss of CYP11A1 activity by cleaving cholesterol to pregnenolone. Thus, we analyzed whether a mutation in the CYP11A1 gene was the reason for the extremely high ACTH levels and PRA activity in the newborn and why the patient's mother experienced difficulty in retaining pregnancies. Our report demonstrates that the presence of homozygous disruptive CYP11A1 mutations may represent a preemptive indication for multiple spontaneous abortion. The mutation identified in this study was isolated from a Mexican newborn whose maternal and paternal families were from the same village and whose families had long and healthy lifespans.

To date, CYP11A1 gene mutations that induce $\mathrm{CAH}$ have been described in only 15 patients (Table 1 ), which is likely due to the fact that it is the sole enzyme maintaining adrenal activity required for the production of all steroids.
Most CYP11A1 gene mutations have been heterozygous and some have appeared at the late onset of puberty. In contrast, we have identified a single nucleotide change at position 857 of the CYP11A1 gene, which results in a nonsense mutation (W286X) and, therefore, a truncated protein (from a 61 to a $31 \mathrm{kDa}$ protein). The patient had very high ACTH levels and PRA activity, and the ACTH level remained higher than normal levels possibly because the mineralocorticoid receptor is not acting at the same level as the glucocorticoid receptor. As the ACTH level remained above the normal range, increased cortisol should then be maintained by the adrenal gland. However, inactivity of the metabolizing enzymes of the adrenal gland resulted in an imbalance in the electrolyte transport from the adrenal gland.

Many of the patients with previously identified CYP11A1 mutations had mothers with a history of miscarriages, and some experienced the very early stage of salt wasting crisis and high ACTH secretion (9). In some cases, the onset of adrenal failure was later, and many were 
Table 1 Mutations in the side chain cleavage enzyme (CYP11A1) causing ambiguous genitalia, sex reversal, past miscarriages and spontaneous abortions.

\begin{tabular}{|c|c|c|c|c|c|c|c|}
\hline Mutations & Ref & $\begin{array}{l}\text { Homozygous/ } \\
\text { heterozygous } \\
\text { (patient) }\end{array}$ & $\begin{array}{l}\text { Onset of adrenal } \\
\text { failure }\end{array}$ & Karyotype & Genitalia & $\begin{array}{c}\text { Maternal } \\
\text { miscarriage/ } \\
\text { abortion } \\
\end{array}$ & Gestation \\
\hline L222P & (3) & Homozygous & 9 years & $46, X Y$ & Normal male & 0 & Full term \\
\hline R360W/R405X & (3) & Heterozygous & 15 days & $46, X Y$ & Micropenis & 1 & Full term \\
\hline L141W/V415E & (3) & Heterozygous & $1-9$ days & $46, X Y$ & Normal female & 0 & Full term \\
\hline c835delA & (3) & Homozygous & 9 days & $46, X Y$ & Normal female & Low $\mathrm{E}_{3}, 2$ & 31 weeks \\
\hline $\begin{array}{l}\text { Frameshift; c835delA } \\
\text { stop/slice }\end{array}$ & (3) & Heterozygous & 8 days & $46, X Y$ & Normal female & Low $\mathrm{E}_{3}, 1$ & Full term \\
\hline R353W & (3) & Heterozygous & 7-9 months & $46, X Y$ & Normal female & 0 & Full term \\
\hline A189V & (3) & Heterozygous & 7-9 months & $46, X Y$ & Normal female & 0 & Full term \\
\hline A359V & (3) & Homozygous & 21 months & $46, X Y$ & Normal female & 2 & Full term \\
\hline$R 232 X$ & (10) & Homozygous & Neonate & $46, X X$ & Normal female & 2 & Post-term \\
\hline $\mathrm{R} 232 \mathrm{X}$ & (10) & Homozygous & Neonate & $46, X X$ & Normal female & 0 & Full term \\
\hline R232X/F215S & (10) & Heterozygous & 1.2 years & $46, X Y$ & Small penis & 0 & Twin at full ter \\
\hline $\mathrm{R} 232 \mathrm{X} / \mathrm{F} 215 \mathrm{~S}$ & (10) & Heterozygous & 4.75 years & $46, X Y$ & Normal male & 0 & Full term \\
\hline $\mathrm{R} 232 \mathrm{X} / \mathrm{F} 215 \mathrm{~S}$ & (10) & Heterozygous & 1.5 years & $46, X X$ & Normal female & 0 & Full term \\
\hline R120X & (10) & Homozygous & Neonate & $46, X X$ & Normal female & 1 & Full term \\
\hline A269V & (3) & Heterozygous & 8 years & $46, X Y$ & Normal male & 0 & Full term \\
\hline A269V & (3) & Heterozygous & 12 months & $46, x X$ & Normal female & 0 & Full term \\
\hline R451W & (3) & & 2 year 10 months & $46, X Y$ & Normal male & 0 & Full term \\
\hline R451W & (3) & & 1 year 3 months & $46, X Y$ & Normal male & 0 & Full term \\
\hline $\begin{array}{l}\text { Insertion of } \mathrm{G} \text { and } \mathrm{N} \\
\text { between D271 } \\
\text { and V272 }\end{array}$ & (3) & Heterozygous & 4 years & $46, X Y$ & Normal female & 0 & Full term \\
\hline W286X & This study & Homozygous & 1 day after birth & $46, X Y$ & Normal female & 3 & Full term \\
\hline
\end{tabular}

either heterozygotes or had undergone gene conversion, likely resulting in a minimum level of pregnenolone-toprogesterone conversion catalyzed by $3 \beta \operatorname{HSD} 2(4,10)$.

Our recent finding shows that steroidogenic protein $3 \beta \mathrm{HSD} 2$ activity requires an association with mitochondrial translocases, including Tim50 or Tim23 of the inner mitochondrial translocase and Tom 22 translocase facing the IMS side of the mitochondria, after entering to the mitochondria (10). In the absence of these mitochondrial translocases, 3 $\beta$ HSD2 and StAR activities were reduced. In the absence of the mitochondrial import receptor, Tom 22 , the alternate OMM-associated protein, Tom20, can facilitate protein import; however, it cannot translocate to the appropriate protein environment and thus becomes inactive. CYP11A1 is a 521 amino acid protein and its N-terminal 39 amino acids are essential for import into the mitochondria (3). In this study, the 286 amino acid CYP11A1 is a truncated protein, which is imported into the mitochondria where its 39 amino acid N-terminal signal sequence is cleaved in a fashion similar to the wild-type protein. Because of the absence of full-length sequence, the CYP11A1 passenger protein sequence could not interact with the electron donating partner of ferrodoxin - ferrodoxin reductase. Thus, the short CYP11A1 is imported into the mitochondria and processed in a similar fashion like wild type, which was not observed for another mitochondrial enzyme 3 $\beta \mathrm{HSD} 2$, which ignored the N-terminal sequence when fused with its N-terminus (10). Thus, CYP11A1 activity requires the passenger protein sequence, which explains why carriers of the CYP11A1 mutation had retained activity.

Declaration of interest

The authors declare that there is no conflict of interest that could be perceived as prejudicing the impartiality of the research reported.

\section{Funding}

The work was initially supported by a grant from National Institutes of Health (HD057876), an intramural research grant from Anderson Cancer Institute and a Seed Grant from the Mercer University School of Medicine (all to H S B)

\section{Patient consent}

Informed consent has been obtained for this study.

Author contribution statement

$\mathrm{J}$ Kaur did the lab/scientific experiments and analyzed the data. H Bose analyzed and interpreted the data and wrote the manuscript. Patient was seen by A Rice, E O'Connor, A Piya, B Buckler. 


\section{References}

1 Bose HS 2011 Mechanistic sequence of mitochondrial cholesterol transport by StAR proteins. Journal of Proteins and Proteomics 2 1-9.

2 Kaur J, Casas L \& Bose HS 2016 Lipoid congenital adrenal hyperplasia due to StAR mutations in a Caucasian patient. Endocrinology and Diabetes Metabolism 2016150119 (doi:10.1530/EDM-15-0119)

3 Miller WL \& Bose HS 2011 Early steps in steroidogenesis: intracellular cholesterol trafficking. Journal of Lipid Research 52 2111-2135. (doi:10.1194/jlr.R016675)

4 Pawlak KJ, Prasad M, Thomas JL, Whittal RM \& Bose HS 2011 Inner mitochondrial translocase Tim50 interacts with 3betahydroxysteroid dehydrogenase type- 2 to regulate adrenal and gonadal steroidogenesis. Journal of Biological Chemistry 286 39130-39140. (doi:10.1074/jbc.M111.290031)

5 Prasad M, Kaur J, Pawlak KJ, Bose M, Whittal RM \& Bose HS 2015 Mitochondria-associated endoplasmic reticulum membrane (MAM) regulates steroidogenic activity via steroidogenic acute regulatory protein (StAR)-voltage-dependent anion channel 2 (VDAC2) interaction. Journal of Biological Chemistry 290 2604-2616. (doi:10.1074/jbc.M114.605808)

6 Bose M, Whittal RM, Miller WL \& Bose HS 2008 Steroidogenic activity of StAR requires contact with mitochondrial VDAC1 and phosphate carrier protein. Journal of Biological Chemistry 283 8837-8845. (doi:10.1074/jbc.M709221200)

7 Meis PJ, Klebanoff M, Thom E, Dombrowski MP, Sibai B, Moawad AH, Spong CY, Hauth JC, Miodovnik M, Varner MW, et al. 2003 Prevention of recurrent preterm delivery by 17 alphahydroxyprogesterone caproate. New England Journal of Medicine 348 2379-2385. (doi:10.1056/NEJMoa035140)

8 Tajima T, Fujieda K, Kouda N, Nakae J \& Miller WL 2001 Heterozygous mutation in the cholesterol side chain cleavage enzyme (p450scc) gene in a patient with 46,XY sex reversal and adrenal insufficiency. Journal of Clinical Endocrinology and Metabolism 86 3820-3825. (doi:10.1210/jcem.86.8.7748)

9 Tee MK, Abramsohn M, Loewenthal N, Harris M, Siwach S, Kaplinsky A, Markus B, Birk O, Sheffield VC, Parvari R, et al. 2013 Varied clinical presentations of seven patients with mutations in CYP11A1 encoding the cholesterol side-chain cleavage enzyme, P450scc. Journal of Clinical Endocrinology and Metabolism 98 713-720. (doi:10.1210/jc.2012-2828)

10 Rajapaksha M, Kaur J, Prasad M, Pawlak KJ, Marshall B, Perry EW, Whittal RM \& Bose HS 2016 An outer mitochondrial translocase, Tom22, is crucial for inner mitochondrial steroidogenic regulation in adrenal and gonadal tissues. Molecular and Cellular Biology 36 1032-1047. (doi:10.1128/MCB.01107-15)

Received in final form 7 September 2016

Accepted 13 September 2016 